\title{
El film como máquina de sentido: Peter Wollen y el estructuralismo británico en la década de 1970
}

\author{
The film as a sense-making machine: Peter Wollen and the British \\ structuralism in the 1970s
}

\section{David Oubiña}

Universidad de Buenos Aires, Buenos Aires, Argentina

doubiniaAretina.ar

\section{Resumen}

Este artículo es una revisión teórica del cineestructuralismo británico y recupera los planteamientos de Peter Wollen en su libro Signs and Meaning in the Cinema que fue fundamental para la constitución de una nueva perspectiva de análisis crítico. Apoyándose en la antropología de Claude Lévi-Strauss, los estructuralistas británicos de los años setenta pensaron los films como un sistema de mensajes gobernados por un código. Frente a los riesgos del "culto a la personalidad" Icomo se verificaba en la noción de autor propuesta por Cahiers du cinéma en los años cincuenta), los críticos vinculados a la revista Screen trabajaron sobre la materialidad de las formas, pensando en la figura del autor como consecuencia y no como fundamento de la obra. El libro de Wollen encarna ese momento de transición donde se revaloriza la figura del espectador, que empezará a ocupar un lugar central en los estudios sobre arte y comunicación.

Palabras clave: Revista Screen, cine-estructuralismo británico, Claude Lévi-Strauss, Peter Wollen.

\begin{abstract}
This article retrieves the proposals of British cinestructuralism and examines Peter Wollen's ideas in his book Signs and Meaning in the Cinema that played a crucial role in the constitution of a new critical perspective. Drawing from Claude Lévi-Strauss' anthropology, the British structuralists during the 1970s conceived films as a system of messages ruled by a code. Facing the risks implied in the "cult of personality" las it could be verified in the notion of auteur proposed by Cahiers du cinéma in the 1950s), the critics associated with the journal Screen worked on the materiality of forms, conceiving the authorial figure as a consequence -not as the origin- of the work. Wollen's book embodies that moment of transition where the figure of the spectator is revalued and begins to perform a central role in art and communication studies.
\end{abstract}

Keywords: Screen Journal, British cine-structuralism, Claude Lévi-Strauss, Peter Wollen. 


\section{Introducción}

Surgida en las páginas de Cahiers du cinéma durante los años cincuenta, la política de los autores es apropiada por las revistas británicas a fines de los sesenta y comienzos de los setenta (Roggen, 2013; Hedling, 2003). Truffaut menciona, por primera vez, la expresión política de los autores en el artículo "Sir Abel Gance" donde cuestiona a quienes valoraban las películas mudas del director y despreciaban sus películas habladas; para él, en cambio, esa distinción resulta absurda porque unas y otras fueron creadas por el mismo director genial y -como sostiene el crítico- los genios no envejecen (1954a). Pensar en autores y no en obras es defender el trabajo del director frente al film de guionista y frente a la ambición de los estudios por obtener un producto.

Esta política de los autores confronta violentamente con la llamada tradition de qualité que distingue a la cinematografía francesa de los años 40 y 50 . Truffaut, en cambio, considera que esas obras tan celebradas son sólo películas de guionistas y que todo su prestigio descansa sobre el valor de las obras literarias elegidas para adaptar a la pantalla, lo cual revela una concepción muy limitada del cine subordinada por completo a la literatura. ${ }^{1} \mathrm{Sin}$ duda resulta provocativo, en ese contexto, asignar la autoría del film a los directores, cuando se sobreentiende que es una tarea de creación colectiva. ${ }^{2}$ Pero lo verdaderamente escandaloso de la política de los autores fue que estos jóvenes críticos elevaban a la categoría de autor a una serie de directores norteamericanos que, hasta entonces, sólo habían sido considerados como meros empleados de los estudios o, en el mejor de los casos, como correctos artesanos: Howard Hawks, Alfred Hitchcock, Otto Preminger, Jacques Tourneur, Samuel Fuller, Preston Sturges, Vincente Minelli y Nicholas Ray (De Baecque, 1991; Bickerton, 2009).

La política de los autores nunca se planteó como una teoría sino más bien como una entronización, un tanto arbitraria, de las preferencias personales del crítico. En la revista Screen, en cambio, el célebre postulado que François Truffaut había tomado de Giraudoux ("no hay obras, sólo hay autores") es obligado a pasar por el paradigma del estructuralismo. Sobre todo, con los estudios de Claude Lévi-Strauss a propósito del mito (1987). Los textos tempranos de Geoffrey Nowell-Smith, Peter Wollen, Jim Kitses, Alan Lovell, Paul Willemen o Ben Brewster forman parte de esa corriente heterogénea que se conoce como autor-estructuralismo o cine-estructuralismo (Henderson, 1973; Brewster, 1971; Eckert, 1973). En busca de una legitimación más cientificista para los estudios sobre cine, los críticos remiten a las innovaciones introducidas por la antropología estructural. Todo esto implica una cierta institucionalización: la transformación de una política [politique] (de los autores) en una teoría [theory] (del autor).

Dice John Caughie: "Lo que el estructuralismo ofreció como práctica crítica fue una manera de analizar objetivamente un corpus de películas para descubrir los patrones temáticos que las informan (...) en vez de la inapropiada modalidad del artista romántico que intencional y consistentemente expresa su propio yo" (1990, p. 126). De Barthes a Metz, Screen transita por los caminos del estructuralismo para desembocar en la naciente semiología como promesa de una aproximación científica al cine. A fines de la década del 60 , esto constituye indudablemente una novedad. Pero, además, esa reformulación de ciertos presupuestos de la teoría del cine tendrá consecuencias que llegan hasta el presente: al revisar las nociones de autor, obra y espectador, la experiencia del estructuralismo abrió nuevas perspectivas que resultarían productivas no sólo para el campo del cine sino también para los estudios culturales y los estudios sobre comunicación (Rosen, 1977; Robins, 1979; Mascarello, 2001).

Este artículo se concentra sobre el libro Signs and Meaning in the Cinema, de Peter Wollen, publicado por primera vez en 1969. La importancia de este texto corre el riesgo de quedar hoy soslayada, no porque se lo haya olvidado sino justamente porque se ha incorporado hasta tal punto a nuestro modo de pensar el cine que tiende a ser naturalizado. La operación de Wollen fue tan novedosa en su momento que, quizás por eso mismo, planteaba una serie de interrogantes que no podía sino dejar abiertos y sin resolución. En sus intentos por escapar a una formulación romántica del autor -tal como había hecho Cahiers du cinéma- el libro de Wollen pone en escena las dificultades a las que se enfrentan ciertos conceptos cuando son apropiados por las nuevas teorías; pero, al mismo tiempo ly ésa es la hipótesis que sostiene el presente ensayo), ese debate interno encarnado por el libro 
conserva su relevancia en la actualidad porque señala un momento de transición y anuncia una revalorización de la figura del espectador que inmediatamente resultará fundamental para la articulación de nuevas perspectivas críticas desde la subalternidad, el feminismo y el tercermundismo. ${ }^{3}$

\section{Estructuralismo británico y teoría del autor en el cine}

\subsection{Cine-estructuralismo}

A diferencia de lo que sucedía en Francia durante la posguerra, en Gran Bretaña el surgimiento del debate sobre cine se asocia a la actividad académica: muy a menudo, los críticos son alumnos o graduados que establecen sus primeros vínculos con las películas gracias a los cine-clubs estudiantiles y que comienzan a escribir en las revistas universitarias: Sequence, Oxford Opinion, Movie (Bolas, 2009; Gibbs, 2013). Cuando Screen irrumpe en la escena británica, en 1969, el enemigo ya no será el cinéma de qualité sino un tipo de crítica demasiado apegada a los liberal values. En el pasaje de un contexto a otro, se han instalado ciertas divergencias: por un lado, una toma de distancia respecto de la práctica cinematográfica (Truffaut o Godard pensaban como cineastas, los redactores de Screen piensan como teóricos) y, por otro, una consolidación de la crítica como campo de acción específico. En la década de 1960, Movie se había presentado como la heredera de Cahiers du cinéma y había usado los postulados sobre el autor para enfrentar el conformismo de revistas como Sight and Sound. Durante los años 70, Screen también persigue la estela de la revista francesa, aunque ya no serán los Cahiers bazinianos: el modelo es el de los Cahiers post-68 que ahora es utilizado para oponerse a Sight and Sound (que representa el establishment) pero también a Movie (que ocupa el lugar de revista moderna, intelectual y provocadoral.

Movie pretende un tipo de lenguaje analítico, alejado de la mirada impresionista. Pero precisamente por eso, sus close readings tienden a excluir cualquier intento profundo de generalización. Movie es una revista de crítica; la perspectiva de Screen, en cambio, es netamente teórica. Significativamente, el título "Movie" hace referencia al objeto -puesto que la revista se ocupa de películas- mientras que la palabra "Screen" involucra el dispositivo: la pantalla es el marco ideológico donde se dan cita las condiciones de producción y de recepción lla revista usa películas para hablar teóricamente sobre el cine). Tal como propone Lovell en su método de autor-estructuralista: "Todo director crea sus films sobre la base de una estructura central y (...) todos sus films pueden ser vistos como variaciones o desarrollos de ella" (1969, p. 47-48). El estructuralismo no sólo habilita a pensar en las obras sino, sobre todo, en un cierto funcionamiento de ellas (los autores serán, entonces, el resultado o una consecuencia de las obras).

La piedra de toque del estructuralismo británico es el libro Luchino Visconti, de Geoffrey NowellSmith: un estudio integral sobre la obra del cineasta hasta 1967 launque, en sucesivas reediciones, el autor agregaría las nuevas películas hasta cubrir un análisis completo de la filmografía). En la introducción, Nowell-Smith explica que la teoría del autor es, para él, un "principio metodológico" en la medida en que permite encontrar conexiones estructurales entre los films más allá de su unidad temática. Y son esas conexiones las que mantienen la unidad y la coherencia de la obra:

\begin{abstract}
Un corolario esencial de la teoría, tal como ha sido desarrollada, es el descubrimiento de que las características definitorias en la obra de un autor no siempre son las que resultan más aparentes. El objetivo de la crítica consiste, entonces, en dejar al descubierto -por detrás de los contrastes superficiales de tema y tratamiento- un núcleo estructural de motivos básicos y recónditos. El patrón formado por estos motivos, que pueden ser estilísticos o temáticos, es lo que le da a la obra de un autor su estructura peculiar y es lo que la define internamente tanto como la distingue de otros cuerpos de obra (2003, p. 10-11).
\end{abstract}

No obstante, Nowell-Smith reconoce que una aproximación exclusivamente estructuralista a las películas de Visconti constituiría un análisis parcial porque se trata de una filmografía cuyos intereses temáticos y sus patrones estilísticos han cambiado mucho con el tiempo. Por eso, aunque conserva la referencia a ciertas continuidades de la obra, el libro propone diferentes análisis específicos de cada film en particular: todavía piensa en Visconti de manera tradicional, como una figura que es 
previa a las películas. En este sentido, no pretende una adscripción completa al estructuralismo sino que lo utiliza como herramienta de análisis. Habrá que esperar la publicación de Signs and Meaning in the Cinema, el año siguiente, para encontrar una perspectiva de estudio que se aproxima a las obras según el método estructural para arribar a una caracterización general sobre el funcionamiento del autor en el cine.

\subsection{Género y autor}

El libro de Peter Wollen tiene un impacto inmediato (Rodowick, 2012). Su influencia en los estudios sobre cine se extenderá más allá de su época y del restringido campo de la semiología. El argumento se desarrolla alrededor de tres ejes: el rescate de Eisenstein como un teórico fundamental, la formulación de una semiología aplicada al cine y la redefinición del concepto de autor como herramienta privilegiada para la reflexión crítica. A propósito de esta cuestión, el texto de Wollen funciona casi como el manifiesto de una nueva manera de pensar el cine alrededor de los autores, retomando las ideas de Cahiers du cinéma pero, a la vez, sometiéndolas a un completo proceso de transformación. El antecedente más cercano es, obviamente, el libro de Nowell-Smith sobre Visconti que Wollen cita para enmarcar sus propias reflexiones dentro de una perspectiva estructuralista. Como queda dicho, en Luchino Visconti las características que definen la obra de un autor lese "núcleo de motivos básicos y con frecuencia recónditos") no son inmediatamente evidentes sino que deben ser descubiertas detrás de lo aparente. Wollen concluye: “Es esta perspectiva estructural, tal como la denomina Nowell-Smith, lo que resulta indispensable para el crítico" (1972, p. 80). También Horizons West (1969), el libro de Jim Kitses, se apoya sobre premisas del pensamiento estructural. La diferencia que introducen los libros de Wollen y de Kitses frente al trabajo pionero de Nowell-Smith radica en la elección de sus objetos de estudio. Porque mientras éste se ocupa de un cineasta europeo, el género resulta central en los análisis de aquéllos: Hawks ya no es un autor porque logra trascender las rígidas normas del género (tal como planteaban los críticos de Cahiers du cinémal, sino que lo es precisamente como resultado de un juego dialéctico entre arquetipos. No a pesar del género sino gracias a la estructura de oposiciones que él determina. En tanto esquema colectivo, el género puede servirse del análisis de los mitos: esta perspectiva no sólo quedaba obligatoriamente afuera del libro sobre Visconti sino que era una dimensión casi inexistente en los artículos iniciales de la política de los autores. En este sentido, la influencia de Lévi-Strauss permite levantar la interdicción que pesaba sobre los géneros en Cahiers.

Los críticos franceses elegían ciertos directores de Hollywood, pero no estaban interesados en el desarrollo histórico de los géneros. Cuando escribían sobre sus directores norteamericanos preferidos, los celebraban como autores contra los géneros: el género importaba como conjunto de convenciones anónimas que aprisionaban a los cineastas y que éstos debían trascender, a través de la puesta en escena, para conquistar un estilo propio. Por eso Rohmer podía admirar a Ford o a Hawks y, aun así, declarar que no le interesaban los westerns. Horizons West, en cambio, considera que el género es fundamental para los realizadores norteamericanos. Va hacia atrás para ir hacia adelante: desarma el esquema autoral de los Cahiers, retrocede en busca de las estructuras colectivas del género (sus "operaciones internas") y hace derivar de allí el esquema temático y estilístico de la obra de cada autor. Así, Anthony Mann, Budd Boetticher y Sam Peckinpah -los tres directores que el libro estudia- encuentran su esencia dentro del western: autor y género se retroalimentan. Dice Kitses:

\begin{abstract}
El western no es sólo los hombres que han trabajado en él. Más que un recipiente vacío que ha sido moldeado por el director, el género es una estructura vital en la que fluye una miríada de temas y conceptos. Como tal, puede proporcionar al cineasta un rango posible de conexiones y un espacio en el que es posible experimentar para dar forma y depurar el tipo de efectos y sentidos hacia los que él se dirige. Tenemos que estar preparados para considerar la idea de que los autores evolucionan y que el género puede ayudar a cristalizar preocupaciones contribuyendo activamente en su desarrollo (1969, p. 26-27).4
\end{abstract}

Kitses invierte la fórmula de Bazin: no es que ciertos directores regresan con insistencia al western para descubrir la esencia del género sino que perseveran en el western porque encuentran allí su propia esencia. Para los críticos estructuralistas británicos, los mecanismos genéricos pue- 
den ser pensados por similitud con el trabajo de los mitos (la repetición de motivos, el sistema de oposiciones, el esquema actanciall. Se trata de estructuras narrativas con funciones fijas, sin autor y conocidas por todos. El western parece un locus especialmente adecuado para poner a prueba esas cuestiones porque es el género cuyo mecanismo más se acerca al funcionamiento de una mitología. No es casual que el libro de Kitses esté dedicado a este género y que Wollen use a Hawks o a Ford como ejemplos privilegiados. Los westerns de Hollywood suelen ocurrir durante el período de las Indian Wars (1865-1890), es decir: el establecimiento de la frontera entre la civilización y el salvaje Oeste que funda la leyenda nacional de los Estados Unidos. Del "genio del sistema" al pensamiento mítico: el recurso a Lévi-Strauss (1972a) permite reestablecer de manera científica la conexión oculta locultada por los críticos de Cahiers) entre el cine americano y sus autores.

\subsection{El modelo estructural}

Para Lévi-Strauss (1972b), el núcleo de un mito se revela mediante el análisis de sus distintas versiones. Por lo general, ese núcleo ha permanecido oculto para los narradores del mito $y$, una vez desentrañado, suele ser muy diferente al sentido de superficie. Se podría decir, entonces, que el sentido no es intencional 0 , al menos, que no es consciente. Si es cierto que los films (los films de género) funcionan de la misma manera, entonces el críticoetnógrafo es quien puede extraer -es decir: elaborar- el significado profundo de una obra que permanecía inaccesible para el propio autor. Es más: el cineasta se construye como autor a posteriori, en la encrucijada de determinados parámetros estructurales propios del género que practica y que insisten a lo largo de su obra. Pero como sostiene Charles Eckert en un artículo temprano sobre los cine-estructuralistas británicos: “Antes de que las películas puedan equipararse a los mitos, tienen que cumplir con una condición fundamental: tienen que originarse en una comunidad con una 'concepción compartida del mundo'. Sólo en tal comunidad puede el sistema dialéctico del mito ser coherente" (1973, p. 49). Eckert indica que la historia del cine se articula a partir de estilos (los cines nacionales, los movimientos internacionales, los estudios) y, a pesar de que esos ordenamientos atentan contra el flujo dinámico del desarrollo artístico, probablemente no son menos arbitrarios que las 'comunidades' que Lévi-Strauss define para su estudio. Reflejan el hecho de que, en general, las películas se producen como esfuerzos comunitarios. En su apogeo, Hollywood parecía una estructura social compleja no muy diferente a las estructuras de familia-clan-pueblo con las que trabaja Lévi-Strauss (1973, p. 49).

Toda la fundamentación del autor-estructuralismo se apoya en la asimilación de las películas a los mitos. No obstante, esa similitud es sólo aparente y más bien superficial. No alcanza para afirmar que las películas constituyen un desarrollo moderno de los mitos. Aunque Eckert adopta una mirada básicamente descriptiva, no deja de criticar a los estructuralistas británicos porque no aplican al pie de la letra los postulados de Lévi-Strauss; sin embargo, lo que resulta problemático es justamente la situación inversa: cuando intentan trasladar literalmente las ideas del análisis estructural sin dar cuenta de las diferencias entre los objetos de estudio. Es evidente que el estudio estructural de los mitos tiene, para Wollen, un valor instrumental; se trata de un modelo que funciona y que, por lo tanto, puede ser apropiado. Esa apropiación (parcial, fragmentaria, localizadal es perfectamente legítima. El problema surge, más bien, cuando los mecanismos empleados por Lévis-Strauss son aplicados de manera mecánica y dogmática en el análisis cinematográfico. Es decir: no cuando Wollen aprovecha -en lo que pueda resultar útil- el método estructural para el análisis de films (puesto que allí también se puede encontrar un "núcleo de motivos reiterados)", sino cuando pretende estudiar los films de un modo muy literal como si fueran un avatar tecnológico de los mitos (por ejemplo, cuando afirma que las películas funcionan igual que los mitos o los cuentos de hadas $y$, por lo tanto, admiten el mismo tipo de aproximación) (Wollen, 1972).

Wollen avanza sobre la estela dejada por Cahiers du cinéma; sin embargo, introduce una serie de modificaciones. $Y$ aunque suele presentarlas como desvíos correctivos, en algunos casos se trata de opciones que entran en franca contradicción con las ideas de los críticos franceses. En la primera línea del capítulo sobre autoría, Wollen contextualiza históricamente su punto de partida: "La política de los autores -la teoría de autor, como la denomina Andrew Sarris- fue desarrollada por un grupo de crí- 
ticos que escribían para Cahiers du cinéma y que la convirtieron en la revista más importante del mundo" (1972, p. 74). Tal como sucedía en la traducción de Sarris, el enunciado parece señalar una sinonimia o, en todo caso, un leve deslizamiento de nomenclatura. Casi una adaptación terminológica que otorgaría al concepto un mayor rigor conceptual. Pero el pasaje de política a teoría no es sólo un variación que aportaría un aspecto más academicista sino que revela la tentativa de convertir esa noción en una categoría científica aplicada al análisis de films. Wollen retiene la opción de los viejos Cahiers por cierto cine popular y por algunos cineastas norteamericanos en particular; pero se aproxima a esa cuestión apoyándose sobre un andamiaje teórico que se nutre del estructuralismo y la semiología. Ya no se trata de una selección más o menos arbitraria de directores (que sobresalen por encima de los demás en la medida en que logran hacer visibles las marcas de su estilo), sino que se ha convertido en el intento por edificar una teoría general cuyos principios todavía hay que establecer.

\section{Peter Wollen: hacia un nuevo concepto de autor cinematográfico}

\subsection{Ford vs. Hawks, Wollen vs. Wood}

La estrategia puesta en práctica por la política de los autores consistió en entronizar la inventiva del genio romántico en el centro del sistema clásico. El clasicismo confía en la existencia de un código universal, es decir homogéneo y relativamente estable lésa es, en definitiva, la utopía del cine de géneros); el romanticismo, en cambio, cree en una unidad orgánica e irrepetible donde cada detalle expresa la totalidad lése es el deseo imposible de la obral. ${ }^{5}$ Pero tanto uno como otro consideran el sentido como una emergencia que puede ser aislada aunque, finalmente, remite a la unidad de una obra o al isomorfismo del código. Enfrentados a esa dicotomía entre Clásico y Romántico que podría organizar los movimientos generales de la historia del arte, los Cahiers no ofrecían una salida al dilema; más bien disimulaban la ausencia de una solución mediante una fórmula astuta y eficaz que consistía en apreciar la individualidad romántica dentro de una gramática clásica construida sobre la uniformidad de lenguaje. De todos modos, el verdadero peligro de la estrategia de Cahiers du cinéma consistió en la frecuente confusión entre auteur y metteur en scène. Wollen distingue:

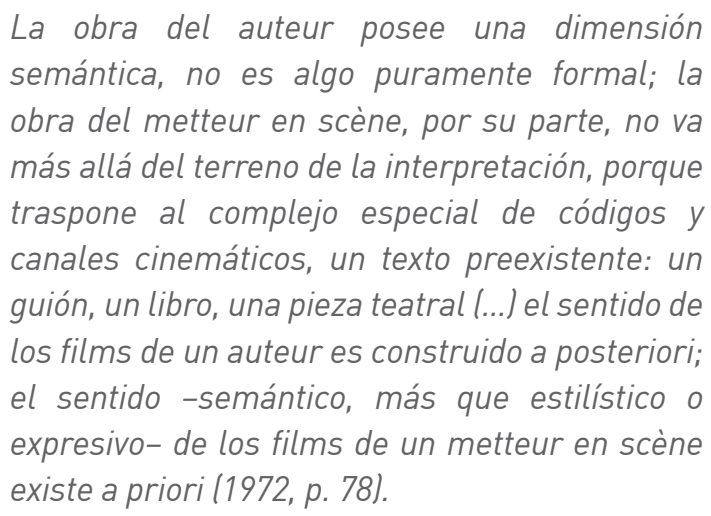

Esta distinción no siempre es tan clara y, por eso, muchos críticos franceses llos macmahonianos, por ejemplo: Michel Mourlet, Pierre Rissiente, Jacques Serguine, Michel Fabre, Marc Bernard) rescataron al metteur en scène por encima del auteur: de ahí el fanatismo por directores como Walsh o Losey, que son elevados a la categoría de íconos. Para Wollen, esos directores sólo muestran solvencia profesional mientras que, en los verdaderos autores, la película involucra una cosmovisión construida cuerpo a cuerpo con los materiales fílmicos. Es una construcción dinámica y, por eso mismo, cambiante: toma en cuenta las transformaciones en la trayectoria de un cineasta y precisa ser completada por la interpretación crítica.

Wollen analiza la obra de Howard Hawks como un test case para la teoría del autor. A lo largo de su carrera y, a pesar de haber practicado los géneros más disímiles, es posible identificar siempre las mismas preocupaciones, los mismos motivos: hay -dice- un homo hawksianus lasí como Barthes afirma que existe un homo racinianus) (1972, p. 81). Pero aquí Wollen se separa de Nowell-Smith, porque la perspectiva estructuralista le permite estudiar esos films no sólo a partir de un núcleo de motivos reiterados sino, también, como un sistema de diferencias y oposiciones. Como afirma Lévi-Strauss, el riesgo de circunscribirse a un señalamiento de las semejanzas es acabar reduciendo todas las ocurrencias singulares a meras variaciones de una matriz abstracta y general lque sólo muestra lo que todos los casos tienen en común y, por lo tanto, no explica nada). Por eso mismo, Wollen sostiene que la crítica estructural debe dar cuenta de los films tanto en su universalidad 
como en su singularidad. Hawks sería un director mucho menos interesante si el corpus de sus películas constituyera un bloque homogéneo; pero su universo cinematográfico se organiza a partir del contraste entre la serie de los adventure dramas y la serie de las crazy comedies. Cada una funciona como la inversión de la otra y, en ese sistema de resonancias y antinomias, la obra adquiere toda su complejidad. Allí, en ese diálogo de opuestos, Hawks encuentra su estatuto de autor: detrás del héroe apolíneo de las películas de aventuras está siempre, como una inversión fantasmática, el antihéroe bizarro de las comedias.

De todos modos, este sistema de oposiciones puede alcanzar en algunos directores un funcionamiento más denso y profundo que en otros. La antinomia básica en las películas de Ford, por ejemplo, es entre "el desierto y el jardín" lque es una adaptación de la oposición naturaleza versus cultura propuesta por Lévi-Strauss); pero aquí esa relación evoluciona a lo largo de la obra. "Mi punto de vista -dice Wollen- es que la obra de Ford es mucho más rica que la de Hawks y que esto se revela mediante un análisis estructural; es la riqueza de la relación cambiante entre antinomias en la obra de Ford lo que hace de él un gran artista, más allá de ser simplemente un indudable autor" (1972, p. 102).6 Así como hay una diferencia entre metteur en scène y auteur, ahora Wollen distingue, también, entre autor y artista: los grandes cineastas no son aquellos que se limitan a reproducir, de un film a otro, un grupo de motivos redundantes sino aquellos que exploran y desarrollan el principio de variación que subyace a la estructura. Es un momento de síntesis que surge al confrontar la totalidad de una obra con cada film singular e implica un desciframiento por parte del crítico. El problema es que, para Wollen, el mayor mérito de Ford sobre Hawks se advierte mediante el análisis estructural; es decir que -en vez de describir una matriz narrativa- las reiteraciones, las variaciones, las oposiciones y las antinomias imponen criterios valorativos. Mientras que la estrategia de Lévi-Strauss consiste en reconducir todas las versiones hacia una forma básica, Wollen parece operar (aunque sin admitirlo) en el sentido contrario: cotejar las variaciones del género le sirve para afirmar que los westerns de Ford son los mejores. Ésa es la crítica de Wood: ¿por qué las antinomias estructurales determinan las diferencias entre una gran película y una mediocre? Robin Wood se propone "de-wollenizar" a Hawks y cuestiona esa metodología porque está basada en abstracciones que no encuentran correspondencias en los ejemplos concretos de los films. ¿Importan las películas concretas o las abstracciones que se puedan extraer de la obra de un artista? (Wood, 2006, p. 251). ${ }^{7}$ La perspectiva "científica y objetiva" propuesta por Wollen es, entonces, tan subjetiva como cualquier otra, con el agravante de que se oculta detrás de la apariencia de un método analítico. Para Wood, eso legitima cualquier preconcepto puesto que la interpretación no hace más que encontrar lo que ha ido a buscar: "No importa qué corte de carne se introduzca en la máquina, siempre sale la misma salchicha estructuralista" (2006, p. 244). ${ }^{8}$

\subsection{Teoría del autor}

Lo cierto es que, para Wollen, el estilo termina desempeñando un papel accesorio y llega a equipararlo con un "ruido" [noise] ya que, en ese nivel, la contribución del director se confunde con una multiplicidad de aportes (del productor, los actores, el director de fotografíal que, en cierto modo, obstaculizan el acceso transparente a la estructura. Los films, entonces, existen más allá del estilo. Dice Wollen: "Los mitos, tal como Lévi-Strauss ha señalado, existen independientemente del estilo, la sintaxis de la oración o el sonido musical, eufónico o cacofónico. El mito funciona 'en un nivel especialmente elevado' donde el sentido consigue 'despegar' del terreno lingüístico en donde sigue rodando" (1972, p. 105). Para Cahiers du cinéma, el autor era el estilo y eso se expresaba en la miseen-scène. Wollen, en cambio, sostiene que el autor es la estructura y eso no surge principalmente de la puesta en escena sino del juego de antinomias que es posible destilar a partir del análisis exhaustivo de un grupo de films. Mientras que el auteurismo romántico iba del director a sus películas lque eran sobredeterminadas por su impronta), el auteurismo estructuralista va de la obra hacia el director (que pasa a ser consecuencia de ella). Cuando Eckert intenta probar que, en los films al igual que en los mitos, el significado puede permanecer oculto para su narrador, afirma que "la unión melliza entre los cineastas y su público produce un extraño Jano de mitos artísticos construidos por hacedores de mitos que sólo son considerados como verdaderos o falsos una vez que han sido creados. Quizás, entonces, el mejor indicio de 
películas auténticamente míticas sean los ratings anuales de taquilla" (1973, p. 50). Pero si los mitos cinematográficos se consagran en la boletería, eso es casi la antítesis de lo que propone el estudio estructural de los mitos en tanto formas culturales anónimas cuya verdad es siempre preexistente. Es obvio que la perseverancia de un relato oral entre sus oyentes tiene motivos muy distintos a los que determinan el éxito comercial de un film.

Según Brian Henderson, la caracterización de Eckert sobre los críticos británicos deja al descubierto la ausencia de una "epistemología autorestructuralista": "En el intento por activar estos textos, Eckert ha activado el escándalo de su falta de fundamento. Al intentar integrarlos, se han deshecho en sus manos" (1973, p. 27). Henderson se pregunta si las modalidades del estudio de los mitos pueden aplicarse a los films y si el estructuralismo puede fusionarse con el auteurismo. Estas preguntas no son idénticas, pero

tanto Wollen como Eckert dan por supuesta esa identidad, aun cuando Eckert hace esfuerzos por librarse de la suposición y entonces su texto le produce algunas grietas. El autorestructuralismo trata las dos cuestiones como una; específicamente, reduce la primera cuestión a la segunda. Por lo tanto, hace que el estudio de los films como mitos dependa de la fusión entre estructuralismo y perspectiva de autor, desestimando otros modos de estudio (Henderson, 1973, p. 32).

En todo caso, si -como quiere Wollen- el film de autor puede entenderse como una "composición" que revela a posteriori la constitución del director en tanto autor, habría que decir, entonces, que el mito es una pura performance cuyo proceso colectivo de enunciación borra cualquier huella de autoría. Según Lévi-Strauss (1968, p. 26), los mitos no tienen origen, ni centro, ni tema, ni autores; mientras que clasificar un grupo de películas como la obra de un cineasta implica definir un origen, un tema, un centro y un autor. Es decir: un funcionamiento opuesto al del mito. Y sin embargo, esta asimilación contradictoria es la que intenta Wollen. Tal como demuestra Henderson (1973, p. 31), Wollen comienza sugiriendo que su "perspectiva estructural" sobre la obra de Hawks tiene afinidades con los métodos aplicados al estudio del folclore y la mitología, pero, en seguida, esas afinidades se convierten en equivalencias casi perfectas que autorizan a examinar los films de Ford con las mismas herramientas que las aplicadas en los cuentos de hadas. Henderson no dice que estructuralismo y teoría del autor sean absolutamente incompatibles; sin embargo, le resulta un proyecto tan poco prometedor que invita a abandonarlo (1973, p. 33).

Para el autor-estructuralismo, el sujeto cognitivo y el objeto del conocimiento son instancias constituidas de antemano y que no se modifican en el proceso. De un lado el observador, del otro el fenómeno. Pero dar por sentado ese vínculo y asumir su carácter inalterable es una de las coartadas ideológicas del empiricismo. ¿En qué medida, entonces, un sistema de interpretación acepta poner en cuestión sus propios fundamentos y presupuestos teóricos?

Por estos motivos, la noción de autor es (de las tres secciones que componen el librol la que parece más vulnerable: casi en seguida sufrirá las mayores transformaciones al ser sometida a los cuestionamientos del post-estructuralismo. En contraste con el capítulo sobre Eisenstein y el capítulo sobre la semiología, las reflexiones sobre la noción de autor son las que de manera más clara evidencian que el libro ha sido escrito en un momento de transición y, por lo tanto, las que escenifican el modo dinámico en que se transforman las categorías teóricas.

\section{Consideraciones finales}

La edición de Signs and Meaning in the Cinema, que se publica en 1972, intenta hacerse cargo del desafío. Wollen hace un agregado a la versión original: "Conclusion (1972)". Allí explica que, al releer su propio libro tres años más tarde, las partes que le resultan más valiosas son los capítulos sobre Eisenstein y sobre la semiología. De manera evidente, la mayor distancia se establece con las ideas planteadas en el capítulo sobre la teoría del autor. En la nueva edición no ha eliminado ese capítulo, pero ha escrito una conclusión para neutralizarlo o atemperarlo. Ese agregado al libro original parece estar destinado a corregir o a reescribir (sobre 
todo: corregir al reescribir) el capítulo sobre teoría del autor.

En 1969, Wollen todavía mostraba su indecisión entre recuperar la noción original de Cahiers o darle un nuevo sentido; es decir, consideraba que el concepto era útil pero que debía ser redefinido puesto que en la acepción francesa quedaba demasiado asociado a la persona individual del director. En 1972 ya ha desistido de cualquier intento por reformular o actualizar la vieja noción; de modo que sólo conserva la denominación len realidad -como se vio- parece conservarla aunque introduce un desplazamiento clave desde política a teoríal pero despliega una definición enteramente diferente sobre qué es un autor. En este sentido, la confrontación entre el capítulo sobre "The auteur theory" y la "Conclusion (1972)" es una instancia privilegiada para advertir la inestabilidad del debate: el momento en que un paradigma de pensamiento es reemplazado por otro, en el interior del mismo libro y ante la mirada de los lectores. ¿Qué es lo que ha sucedido entre la publicación de Signs and Meaning in the Cinema y su reedición? La "Conclusion (1972)" comienza con una declaración: "Volviendo la vista atrás sobre este libro, incluso luego de un breve lapso de tiempo, lo que me sorprende es que fue escrito al comienzo de un período de transición que todavía no ha concluido. Lo que marca a este período, creo, es el demorado encuentro del cine con el 'movimiento moderno' en las artes" (1972, p. 155). En la cultura post-68, los conceptos de artista y de autor len el sentido romántico o estructuralista) serían rechazados (Harvey, 1978; Heath, 1981; Rodowick, 1994; Rosen, 2008).

Wollen hace un esfuerzo por conservar la figura del director, pero ya no entendida como singularidad creadora sino como coartada para denominar una construcción o un desciframiento crítico de las estructuras significativas del film. Allí donde leemos "John Ford" no habría que entender la persona sino la denominación que se le da al resultado de una operación crítica que destila una configuración de sentidos a partir de un grupo de películas realizadas por el mismo director. El autor, entonces, es un "catalizador inconsciente" de sentidos no intencionales:

La estructura se asocia a un director singular, un individuo, no porque haya desempeñado el rol de artista, expresándose o expresando su visión en el film, sino porque es mediante la fuerza de sus preocupaciones que un sentido inconsciente y no intencional puede descifrarse allí, usualmente para sorpresa del propio individuo involucrado. El film no es una comunicación sino un artefacto inconscientemente estructurado de determinada manera. El análisis de autor no consiste en retrotraer el film a sus orígenes, a su fuente creadora. Se trata de rastrear una estructura (no un mensaje) dentro de la obra que luego puede ser asignada post factum a un individuo, el director, sobre bases empíricas (Wollen, 1982, p. 167-168).

Por esa razón, para Wollen ya no es una prioridad elaborar "análisis de autor" sobre Hollywood. Si eso sirvió, en algún momento, fue para desacreditar la aparente superioridad del cine de arte asociado a la cultura elevada y separado de sus raíces en la cultura popular. Así como hasta mediados de los años 60, Godard había creído en las posibilidades de reinterpretar los géneros del cine norteamericano y ahora, sin embargo, ha tomado otro camino. Es evidente que Hollywood no puede ser ignorado pero, justamente, porque se hace necesario confrontar con sus códigos dominantes. El futuro del cine radica en su capacidad para poner en cuestión sus propios fundamentos y en mostrar las contradicciones de su lenguaje. Wollen advierte la necesidad de un cambio, aun cuando todavía se muestre indeciso sobre la dirección que debería tomar. Si Godard -como siempre- señala el camino con su grupo de cineastas militantes Dziga Vertov, es porque ha entendido que no se trata de desarrollar obedientemente las potencias del cine sino de interrogar y de cuestionar sus códigos (Wollen, 1982). Una película no es un medio de expresión y comunicación; es -y aquí Wollen cita a Octavio Paz- una "máquina para producir sentido". Esos sentidos no vienen dados sino que son producidos en la visión del film, en un diálogo siempre renovado entre sujeto y objeto. Hay que observar un proceso dinámico. Ni el autor ni la estructura, ahora se trata del texto: “Más que el sistema de transporte que comunica un producto terminado, el texto es la fábrica donde se elabora el pensamiento" (p. 164).

Por eso el nuevo final del libro propone un tono profético: "Es posible que el período de transición en el que acabamos de ingresar pueda derivar en 
victorias para la vanguardia que está surgiendo" (p. 174). De esa manera, Wollen se afirma en la convicción de que el film no es un medio transparente y allí se abren diversas posibilidades para un tipo de análisis más radicalizado. En efecto, sus trabajos posteriores se dedicarán a explorar "contra-estrategias", no sólo en el cine sino también en la fotografía y las artes plásticas: de qué manera las formas dominantes del arte son contestadas por las vanguardias y por los discursos estéticos de oposición. ${ }^{9}$

A Woollen ya no le interesa el autor como individuo y ni siquiera como estructura. La noción de auto- ría se diluye en un proceso inestable, inubicable, incontrolable: pertenece al texto pero es producida por el espectador y, antes que fijar un sentido, se ocupa de reconstruirlo. Si en la primera edición de su libro, Wollen intentaba negociar entre auteurismo y estructuralismo, ahora quiere abandonar el estructuralismo hacia una noción post-estructuralista del autor como construcción textual. En ese movimiento, se revaloriza la figura del espectador que, en los años siguientes, pasará a ocupar un lugar central en los estudios subalternos, en la perspectiva feminista o en las propuestas del cine del Tercer mundo.

\section{Notas}

1. Frente a la proliferación de películas norteamericanas en la posguerra, el cinéma de qualité (Claude Autant-Lara, Yves Allegret, René Clément, Jean Delannoyl constituyó, en un principio, una defensa del cine nacional. Sobre los cuestionamientos de Truffaut al cinéma de qualité, véase su célebre artículo "Une certaine tendance du cinéma français". Para una defensa contemporánea a los ataques de Truffaut, véase Barrot (1953).

2. Véase Howard Becker (2008), Los mundos del arte (en especial, el capítulo 1: “Mundos de arte y actividad colectiva").

3. Sobre la figura del espectador en relación a estas perspectivas véanse, por ejemplo, los trabajos de Spivak (1985), Mulvey (1975) y Solanas-Getino (1973).

4. Años más tarde, Kitses (1979) revisa y amplía el libro en una nueva edición que incluye capítulos sobre Ford, Eastwood y Leone (Horizons West: Directing the Western from John Ford to Clint Eastwood, British Film Institute, Londres, 2004).

5. Véase la serie de artículos que Rohmer publica en Cahiers du cinéma a lo largo de 1955 y que, más tarde, reúne en un libro (2010).

6. Sobre la oposición entre naturaleza y cultura en Lévi-Strauss, véase la "Introducción" a Las estructuras elementales del parentesco (1998).

7. Véase también John Murray, “Robin Wood and the Structural Critics" (1971).

8. Resulta inevitable pensar que la predilección de Wollen por John Ford es un punto contencioso fren-

te a la manifiesta admiración que Wood confiesa por Howard Hawks. Pero, también, es un ajuste de cuentas con Cahiers du cinéma que siempre había valorado más a éste que a aquél. Recién a mediados de los 60, cuando la revista es ocupada por una nueva generación de críticos (Comolli, Narboni, Daney, Biette), Ford empieza a ser considerado indiscutidamente como un gran artista.

9. En "The Two Avant Gardes", Wollen reconstruye el debate entre cineastas abstractos y cineastas posbrechtianos acerca de qué forma de negatividad articularía mejor la noción de un cine crítico: una vanguardia pictórica (Stanley Brackhage, Hollis Frampton, Paul Sharits, Malcolm LeGricel y una vanguardia literaria (Jean-Luc Godard, Miklos Jancso, Nagisa Oshima, Jean-Marie Straub y Danielle Huillet). Para la vanguardia pictórica la narración es un elemento exterior, que fue impuesto por la escuela realista y que ha obturado las auténticas posibilidades de expresión del cine. Wollen considera, en cambio, que el antiilusionismo modernista debería cruzarse con la referencialidad propia del cine en una "estética posbrechtiana": no se trata de abandonar la representación sino de mostrar los procedimientos que la articulan (1982). El punto de inflexión, en este sentido, es el Grupo Dziga Vertov al que Wollen le dedica un artículo fundamental: "Godard and Counter-cinema: Vent d'Est". Frente a las formas dominantes del cine realista clásico (pero también frente al realismo baziniano, que se apoyaba en una supuesta ontología fotográfica), el Counter-cinema del Grupo Dziga Vertov abre el camino para una estética comprometida con el radicalismo político y la experimentación formal en abierto enfrentamiento con el cine convencional (1982). 


\section{Referencias}

Barrot, J. P. (1953). Sept ans du cinéma français: 1945-1952. París: Éditions du Cerf.

Becker, H. (2008). Los mundos del arte. Buenos Aires: Universidad Nacional de Quilmes.

Bickerton, E. (2009). A Short History of Cahiers du cinéma. Londres: Verso.

Brewster, B. (1971). Structuralism in Film Criticism. Screen 12(1), 49-58.

Bolas, T. (2009). Screen Education. From Film Appreciation to Media Studies. Bristol: Intellect Books.

Caughie, J. (1990). Theories of Authorship. Londres: Routledge.

De Baecque, A. (1991). Histoire d'une revue (Tome l: À l'assault du cinéma 1951-1959 y Tome II: Cinéma, tours détours 1959-1981). París: Cahiers du cinéma.

Eckert, Ch. (1973). The English Cine-Structuralists. Film Comment, 9(3), 46-51.

Gibbs, J (2013). The Life of mise en scène. Visual Style and British Film Criticism, 1946-78. Manchester: Manchester University Press.

Harvey, S. (1978). May '68 and Film Culture. Londres: British Film Institute.

Heath, S. (1981). Questions of Cinema. Bloomington: Indiana University Press.

Hedling, E. (2003). "Lindsay Anderson: Sequence and the Rise of Auterism in 1950s Britain". En: Mackillop, I. \& Sinyard, N. (eds.). British Cinema in the 1950s: A Celebration. Manchester: Manchester University Press.

Henderson, B. (1973). Critique of Cine-Structuralism (Part I). Film Quarterly, 27(1), 25-34. https://doi:10.2307/1211450.

Kitses, J. (1969). Horizons West. Anthony Mann, Budd Boetticher, Sam Peckinpah: Studies of Authorship within the Western. Londres: Thames \& Hudson.

Lévi-Strauss, C (1998). Las estructuras elementales del parentesco. Barcelona: Paidós.

Lévi-Strauss, C. (1987). Antropología estructural, México D. F.: Paidós.

Lévi-Strauss, C. (1972a). “El estudio estructural del mito”. En: Leach, E. (comp.). Estructuralismo, mito y totemismo. Buenos Aires: Nueva visión.

Lévi-Strauss, C. (1972b). “La gesta de Asdiwal”. En: Leach, E. (comp.). Estructuralismo, mito y totemismo, Buenos Aires: Nueva visión.

Lévi-Strauss, C. (1968). Mitológicas I: Lo crudo y lo cocido, México D. F.: Fondo de Cultura Económica.

Lovell, A. (1969). Robin Wood. A Dissenting View. Screen, 10(2), 42-55. https://doi.org/10.1093/ screen/10.2.42.

Mascarello, F. (2001). A screen-theory e o espectador cinematográfico: un panorama crítico. Novos olhares 8, 13-28.

Mulvey, L. (1975). Visual Pleasure and Narrative Cinema. Screen 16 (3), 6-18.

Murray, J. (1971). Robin Wood and the Structural Critics. Screen, 12(3), 101-110. https://doi. org/10.1093/screen/12.3.101.

Nowell-Smith, G. (2003). Luchino Visconti. Londres: British Film Institute. 
Robins, K. (1979). Althusserian Marxism and Media Studies: The Case of Screen. Media, Culture and Society 1(4), 355-370.

Rodowick, D. (1994). The Crisis of Political Modernism. Criticism and Ideology in Contemporary Film Theory. Berkeley: University of California Press.

Rodowick, D. (2012). "Foreword to the Fifth Edition". En: Wollen, P. Signs and Meaning in the cinema. Londres: Palgrave Macmillan.

Roggen, S. (2013). No Quarterly Can Be Too Personal: How Sequence Provided a Pragmatic Alternative to the Politique des Auteurs. Journal of British Cinema and Television 10(2), 340-357.

Rohmer, É. (2010). Le celluloïd et le marbre (suivi d'un entretien inédit avec Noël Herpe et Philippe Fauvell. París: Éditions Léo Scheer.

Rosen, P. (1977). Screen and the Marxist Project in Film Criticis". Quarterly Review of Film Studies 2(3), 273-287.

Rosen, P. (2008). “Screen and 1970s Film Theory”. En: Nash, M. (ed.), Screen Theory Culture. Hampshire: Palgrave MacMillan.

Solanas, F. \& Getino, O. (1973). Cine, cultura y descolonización. Buenos Aires: Siglo XXI.

Spivak, G. (1985). Can the Subaltern Speak? Speculations on Widow-Sacrifice. Wedge 7/8, 120-130.

Truffaut, F. (1954a). Sir Abel Gance. Arts, 479, 1-7.

Truffaut, F. (1954b). Une certaine tendance du cinéma français. Cahiers du cinéma, 31, 15-29.

Wollen, P. (1972). Signs and Meaning in the Cinema. Bloomington: Indiana University Press.

Wollen, P. (1982). Readings and Writings: Semiotic Counter-strategies. Londres: Verso Books.

Wood, R. (2006). Personal Views: Explorations in Film. Detroit: Wayne State University Press.

- Sobre el autor:

David Oubiña es Doctor en Letras, Universidad de Buenos Aires. Es investigador del CONICET y profesor de Pensamiento audiovisual (UBA). Es autor del libro El silencio y sus bordes. Modos de lo extremo en la literatura y el cine (FCE, 2011).

- ¿Cómo citar?

Oubiña, D. (2020). El film como máquina de sentido: Peter Wollen y el estructuralismo británico en la década de 1970. Comunicación y Medios, (41), 42-53, doi: 10.5354/07191529.2020 .53135 